\title{
A Case of Leukaemia Cutis Presenting as Generalized Erythematous Nodules
}

The Editor,

Sir,

A 62-year old female presented with generalized erythematous papules and nodules on the trunk and limbs for two weeks. On physical examination, multiple, non-tender, erythematous papules and nodules, diameters ranging from 0.3 to $1 \mathrm{~cm}$ were observed on the trunk and extremities (Fig. 1).

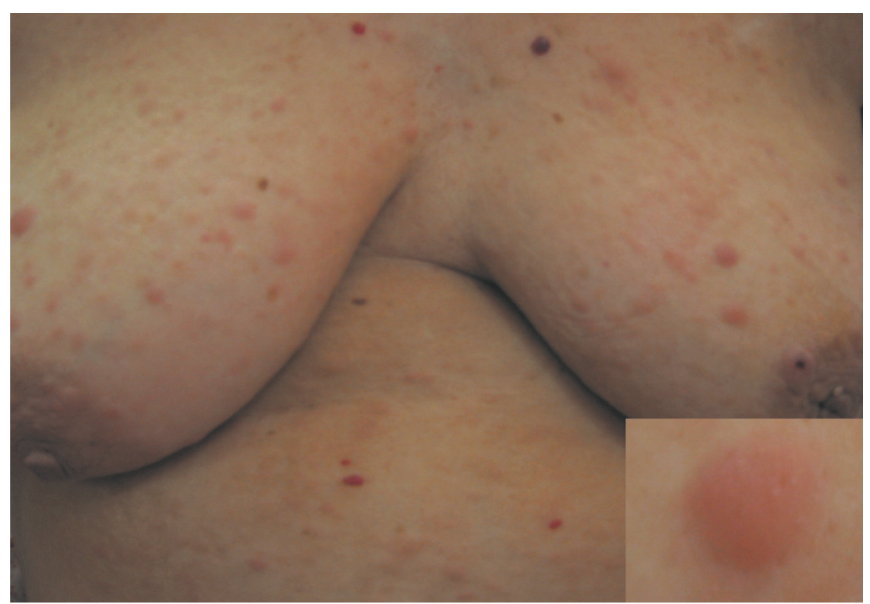

Fig. 1: Generalized erythematous infiltrated papules and nodules on the chest.

The routine laboratory investigations were; white blood cell: $108.8 \times 10^{9} / \mathrm{L}$, haemoglobin: $6.3 \mathrm{~g} / \mathrm{dL}$, platelet: $105 \times 10^{9} / \mathrm{L}$ and lactate dehydrogenase (LDH): $568 \mathrm{U} / \mathrm{L}$. The diagnosis of leukaemia was considered with laboratory tests. Peripheral blood smear showed blast cells. Bone marrow cytology was compatible with the peripheral blood smear. In the flow cytometry, morphologically atypical monoblasts and myeloblasts were located in the granulocyte/monocyte region (85\%). High expressions of CD13, CD33, CD11b, CD14, myeloperoxidase and human leukocyte antigen - antigen D related (HLA-DR) were detected. A punch biopsy was taken from the skin lesions. The biopsy specimen showed an atypical cellular infiltration diffusely located in the dermis sparing of the upper papillary dermis.

Immunohistochemical stains were positive for leukocyte common antigen [LCA] (Fig. 2) and negative for pancytokeratin.

Leukaemia cutis (LC) with the French-American-British (FAB) classification systems subtype acute myeloid leukaemia-M4 (AML-M4) was diagnosed with these findings.

Leukaemia cutis (LC) is the infiltration of leukaemic cells into the epidermis, dermis, or subcutis (1). Incidence of LC varies from less than 5\% to $40 \%$. Cutaneous involvement is more common in the M4 and M5 subtypes of AML. Generally, LC occurs after diagnosis of myeloid leukaemia, but it

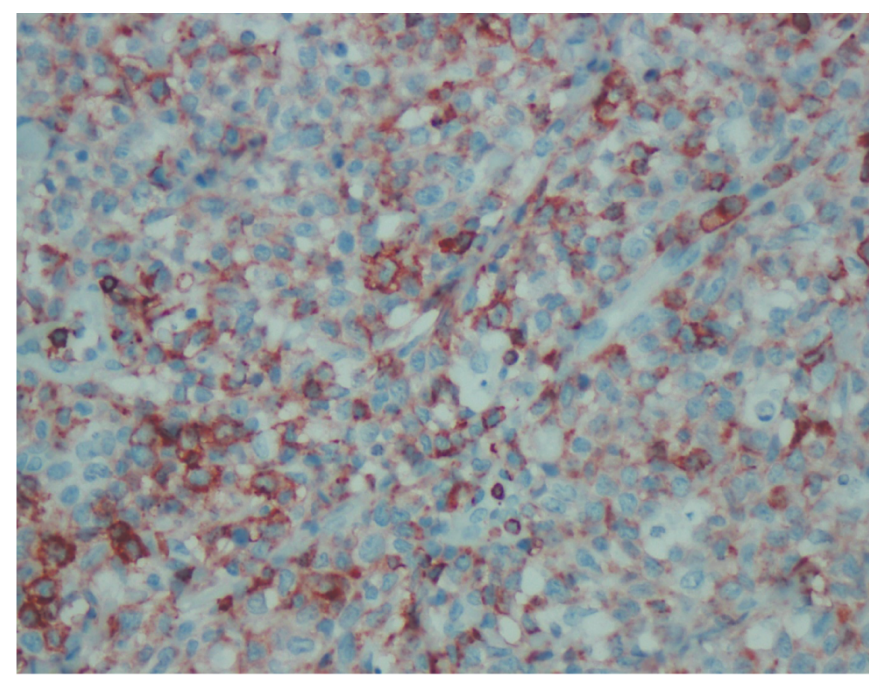

Fig. 2: Immunohistochemical stains were positive for leukocyte common antigen (original magnification $\mathrm{x} 400$ ).

can be seen simultaneously, after or prior to the diagnosis of underlying leukaemia (2).

Skin manifestations of leukaemia are classified into two groups: specific and non-specific. Specific findings called leukaemia cutis are due to leukaemic infiltration of the skin and usually seen as localized or disseminated papules, nodules and plaques with violaceous or reddish-brown colour (3). Non-specific skin manifestations may include maculopapular rash, purpura, excoriation, secondary skin infections, and reactive dermatoses such as Sweet's Syndrome and pyoderma gangrenosum (1).

Diagnosis of LC is based on skin biopsy, immunophenotyping, and $\mathrm{B}$ or $\mathrm{T}$ cell receptor rearrangement studies. Peripheral blood smear and bone marrow biopsy also help in the diagnosis. Histopathology of myeloid LC shows immature myeloid cells that are usually located in the dermis and subcutis with sparing of the upper papillary dermis (4).

There is no specific treatment for LC; the treatment of the underlying leukaemia improves the skin lesions (5). Radiotherapy and whole-body electron-beam irradiation are also considered as alternative treatments for widespread or resistant skin involvement. Leukaemia cutis indicates poor prognosis $(3,5)$.

In our patient, skin lesions were the first sign of underlying leukaemia. The patient was referred to the haematology clinic, but died after one week, while receiving chemotherapy, probably, due to blast crisis. Consideration of LC in the differential diagnosis of suddenly emerged generalized nodules is important to reduce morbidity and mortality.

Keywords: Acute myeloid leukaemia, leukaemic infiltration, myeloperoxidase 
SO Gok, AA Belli, E Dervis

From: Haseki Training and Research Hospital, Department of Dermatology, Mugla Sitki Kocman University Training and Research Hospital, Department of Dermatology, Haseki Training and Research Hospital, Department of Dermatology.

Correspondence: Dr AA Belli, Mugla sitki Koeman University Training and Research Hospital, Department of Dermatology. E-mail:dr_asliakin@hotmail.com

\section{REFERENCES}

1. Zhenying Z, Xiaoming L, Yongjun P, Shixin H. A case of leukemia cutis presenting as histiocytoid Sweet's syndrome. Int J Dermatol 2013; 52: $1338-41$.
2. Rashid BA, Houshmand EB, Heffernan MP. Skin manifestations of bone marrow and blood disorders. In: Wolff K, Goldsmith LA, Katz SI, Gilchrest BA, Paller AS, Leffell DJ, eds. Fitzpatrick's Dermatology in General Medicine, 7th ed. New York: McGraw-Hill; 2008; 1384-5.

3. Lee JI, Park HJ, Oh ST, Lee JY, Cho BK. A case of leukemia cutis at the site of a prior catheter insertion. Annals of Dermatology 2009; 21: 193 6.

4. Cibull TL, Thomas AB, O'Malley DP, Billings SD. Myeloid leukemia cutis: a histologic and immunohistochemical review. J Cutan Pathol 2008; 35: $180-5$.

5. Pinto B1, Dhir V, Dambalkar A, De D, Kumar M, Sharma P. Bullous lesion with central umbilication in leukemia. Int J Dermatol 2014; 53: 145 6. 